\title{
Airway wall thickness in patients with near fatal asthma and control groups: assessment with high resolution computed tomographic scanning
}

\author{
Nasser Awadh, ${ }^{\star}$ Nestor L Müller, Chan S Park, Raja T Abboud, J Mark FitzGerald
}

\begin{abstract}
Background-Airway wall thickening has been observed in post mortem studies of patients with asthma. Assessment of airway wall thickening by high resolution computed tomographic (HRCT) scanning has been reported in experimental studies. We have used HRCT scanning to measure airway wall thickness at the segmental and subsegmental levels in 40 patients with asthma and 14 normal controls.
\end{abstract}

Methods-The subjects were prospectively divided into four age and sex matched groups: 14 patients with a history of near fatal attack of asthma (NFA; group 1), 12 patients with moderate asthma (group 2), 13 patients with mild asthma (group 3), and 14 normal controls (group 4). All subjects were non-smokers. High resolution ( $1 \mathrm{~mm}$ collimation) CT scans of the chest were done at five different levels. Results-The mean (SD) forced expiratory volume in one second $\left(\mathrm{FEV}_{1}\right)$ was 68 (20)\% of predicted for group 1, 73 (12)\%

Respiratory Division, Department of

Medicine

$\mathrm{N}$ Awadh

R T Abboud

J M FitzGerald

Department of

Radiology

C S Park

N L Müller

Vancouver Hospital and Health Sciences Centre, University of British Columbia,

Canada

Correspondence to: Dr J M FitzGerald, Respiratory Clinic,

Vancouver Hospital and Health Sciences Centre, 2775 Heather Street,

Vancouver, British Columbia

V5Z 1M9, Canada.

${ }^{\star}$ Current address:

Department of Medicine,

Kuwait University, PO Box

16789, Al-Qadsia 35859,

Kuwait.

Received 22 August 1997 Returned to authors 11 November 1997

Revised version received

7 January 1997

Accepted for publication

8 January 1997 for group 2, 102 (12)\% for group 3, and 103 (12)\% for group 4 . The ratio of airway wall percentage wall area (WA\%) defined as (wall area/total airway area) $\times 100$ were used to compare airway wall thickness between the groups. The mean (SD) T/D and WA\% were $0.27(0.05)$ and $78.0(9.2) \%$ for group $1,0.27(0.05)$ and $78.8(9.2) \%$ for group $2,0.25(0.04)$ and $74.2(7.5) \%$ for group 3, and $0.23(0.04)$ and $70.9(8.2) \%$ for group $4 . T / D$ and WA\% were not significantly different between groups 1 and 2 . However, both groups 1 and 2 had higher T/D and WA\% than either group 3 or 4 (p $<0.001$ ) and group 3 had a higher T/D and WA\% than group $4(p<0.03)$.The differences $(95 \% \mathrm{CI})$ between the groups in WA\% were $7.1 \%$ (0 to 14.4 ) for groups 1 and $4,3.8 \%(-3.4$ to 10$)$ for groups 1 and 3, and $3.3 \%(-4.4$ to 10$)$ for groups 3 and 4 . The differences between the groups in $T / D$ and WA\% were noted both for those with airways with a luminal diameter of $>2 \mathrm{~mm}$ and those with a luminal diameter of $\leqslant 2 \mathrm{~mm}$.

Conclusions-All the patient groups had greater airway wall thickening than the normal subjects as assessed by HRCT scanning, but patients with more severe asthma had greater airway wall thickening than those with mild asthma. The thickness to outer diameter (T/D) and the methodology described in this study may be useful in assessing airway calibre in early intervention studies with antiinflammatory therapy.

(Thorax 1998;53:248-253)

Keywords: near fatal asthma; airway wall thickness; high resolution computed tomography

Bronchial asthma is a heterogeneous disease characterised by reversible airway obstruction. ${ }^{1}$ It varies in severity from mild episodic attacks to life threatening ones. The nature of bronchial asthma as an inflammatory disease has been well recognised. ${ }^{2}$ Airways of patients who die from asthma have thickened walls. ${ }^{3-7}$ This airway wall thickening results from mucosal infiltration with inflammatory cells, smooth muscle hypertrophy, deposition of connective tissue, and mucous gland hyperplasia. It involves all layers of the airway wall including the muscle membrane and the adventitia.

Apart from necropsy studies which in themselves are limited in number, it has been difficult to examine airway architecture in patients with asthma. High resolution computed tomographic (HRCT) scanning has been used to study parenchymal and airway abnormalities in patients with asthma ${ }^{8}{ }^{9}$ but the scans in these studies were interpreted subjectively. In these studies bronchial dilatation, mucoid impaction, and bronchial thickening were frequent findings in patients with asthma. These abnormalities were mainly seen in patients with severe asthma. Furthermore, HRCT scanning has been used to study the mechanism and site of airway narrowing in experimental models of asthma. ${ }^{1011}$

There are no studies which provide actual airway dimensions in patients with a range of asthma severity. Boulet and colleagues ${ }^{12}$ measured wall thickness of the bronchus intermedius and used it to study the bronchial responsiveness in patients with asthma. There are no published studies comparing airway wall thickness in patients with a history of near fatal asthma (NFA), less severe forms of asthma, and normal controls. We therefore undertook this study to measure the airway wall thickness in patients with asthma. We evaluated the bronchi at the segmental and subsegmental level using a modified HRCT technique.

Methods

SUBJECTS

We prospectively studied 40 asthma patients and 14 normal controls. Asthma was defined 
Table 1 Patient characteristics, lung function and medication use in group 1 (near fatal asthma), group 2 (moderate asthma), group 3 (mild asthma), and group 4 (normal controls)

\begin{tabular}{|c|c|c|c|c|}
\hline & Group $1(n=15)$ & Group $2(n=13)$ & Group $3(n=12)$ & Group $4(n=14)$ \\
\hline $\mathrm{M} / \mathrm{F}$ & $4 / 11$ & $3 / 10$ & $4 / 8$ & $5 / 9$ \\
\hline Mean (SD) age (years) & $45(12)$ & $46(10)$ & $42(12)$ & $42(11)$ \\
\hline Mean (SD) duration of asthma (years) & $25(16)$ & $23(13)$ & $28(15)$ & NA \\
\hline Atopy (yes/no) & $8 / 7$ & $8 / 5$ & $7 / 5$ & NA \\
\hline Inhaled steroids & All & All & 6 & \\
\hline Theophylline & 3 & 2 & None & \\
\hline Systemic steroids & 2 & 2 & None & \\
\hline Mean (SD) $\mathrm{FEV}_{1}\left(\%\right.$ predicted) ${ }^{\star}$ & $68(8)$ & $73(11)$ & $102(12)$ & $103(12)$ \\
\hline Mean (SD) RV (\% predicted)t & $145(27)$ & $168(33)$ & $111(24)$ & ND \\
\hline Mean (SD) FRC ( $\%$ predicted) $†$ & $131(20)$ & $140(23)$ & $110(15)$ & ND \\
\hline Mean (SD) TLC (\% predicted) & $113(10)$ & $119(14)$ & $115(10)$ & ND \\
\hline
\end{tabular}

$\mathrm{FEV}_{1}=$ forced expiratory volume in one second; RV = residual volume; FRC = functional residual capacity; TLC = total lung capacity; $\mathrm{NA}=$ not available, $\mathrm{ND}=$ not done.

*There was no significant difference between groups 1 and 2, but both groups were significantly different from either group 3 or 4 $(\mathrm{p}<0.001)$.

†Groups 1 and 2 had higher RV and FRC than group $3(\mathrm{p}<0.03)$.

according to American Thoracic Society criteria. ${ }^{13}$ All the patients with asthma had evidence of reversible airway obstruction on spirometric testing before and after bronchodilators. Asthma patients were divided into three groups according to severity of asthma. Group 1 consisted of patients with a history of a near fatal attack of asthma (NFA), group 2 comprised patients with moderate asthma requiring daily bronchodilator treatment and at least $1000 \mu \mathrm{g}$ beclomethasone or equivalent daily, group 3 consisted of patients with mild asthma taking intermittent bronchodilators with or without inhaled steroids and $\mathrm{FEV}_{1}$ more than $80 \%$ of predicted normal, and group 4 consisted of normal controls. Near fatal asthma was defined as an acute attack requiring mechanical ventilation $(n=13)$ or the presence of hypercapnia $(\mathrm{pH} 7.01 ; \mathrm{n}=1)$. All patients in group 1 had their episode of NFA at least one year or more prior to the study. Asthma patients were recruited from a general respiratory clinic. Normal controls had no history of wheeze or asthma and normal spirometric data. The subjects in each group were matched for age and sex, and asthma patients were matched for the duration of asthma. All subjects were life time nonsmokers. The study was approved by the Uni- versity of British Columbia Human Ethics committee and all subjects gave written informed consent.

\section{EVALUATION}

Clinical and demographic data were obtained using a standardised interview form. Information collected included age, sex, duration of asthma, frequency of asthma exacerbations, admissions to hospital including any ICU admissions, and current treatment. Baseline spirometric data, bronchodilator response, and lung volumes were obtained for all asthma patients. Normal controls had spirometric tests only. All subjects had a modified HRCT scan of the lungs within one week of the pulmonary function tests. The patients were evaluated when they were stable with no asthma exacerbation in the two weeks prior to their evaluation for the study. Atopic status was determined by skin prick testing to extracts of six common allergens: house dust mite, cat and dog dander, mixed tree pollens, mixed grass pollens, and molds. The allergen extracts were obtained from Bencard Laboratory, Toronto, Ontario. Atopy was defined as a positive skin reaction to at least one allergen.

Table 2 Results of bronchial wall measurements by HRCT scanning

\begin{tabular}{lllll}
\hline & Group 1 & Group 2 & Group 3 & Group 4 \\
\hline No. of bronchi evaluated per patient & $19.3(6.4)$ & $20.4(6.3)$ & $20.5(6.5)$ & $18.6(5.9)$ \\
Total number of bronchi per group & 288 & 266 & 246 & 261 \\
Mean (SD) T (mm) $\dagger$ & $1.28(0.37)$ & $1.21(0.38)$ & $1.12(0.24)$ & $1.09(0.24)$ \\
Mean (SD) T/D ratio $\dagger$ & $0.27(0.05)$ & $0.27(0.05)$ & $0.25(0.04)$ & $0.23(0.04)$ \\
Mean (SD) WA\% & $78(9.2)$ & $78.8(9.2)$ & $74.2(7.5)$ & $70.9(8.2)$ \\
\hline
\end{tabular}

$\mathrm{T}=$ thickness $; \mathrm{D}=$ outer diameter; WA $\%$ = percentage wall area.

$\star$ There was no statistically significant difference between the groups.

†There was no significant difference between groups 1 and 2, but both groups were significantly greater than either group 3 or 4 (p $<0.001)$ and group 3 was significantly greater than group $4(\mathrm{p}<0.01)$.

Table 3 Wall thickness to bronchial diameter(T/D) and wall area (WA\%) in small and large airways

\begin{tabular}{|c|c|c|c|c|}
\hline & Group 1 & Group 2 & Group 3 & Group 4 \\
\hline \multicolumn{5}{|l|}{ Small airways $\leqslant 2 \mathrm{~mm}$} \\
\hline $\mathrm{n}$ & 141 & 159 & 117 & 95 \\
\hline Mean (SD) T/D ratio* & $0.3 .0(0.04)$ & $0.30(0.04)$ & $0.28(0.03)$ & $0.26(0.03)$ \\
\hline Mean (SD) WA \%* & $84.0(5.8)$ & $83.8(5.7)$ & $79.8(4.5)$ & $78.2(4.9)$ \\
\hline \multicolumn{5}{|l|}{ Large airways $>2 \mathrm{~mm}$} \\
\hline $\mathrm{n}$ & 147 & 107 & 129 & 166 \\
\hline Mean (SD) T/D ratio * & $0.24(0.04)$ & $0.24(0.04)$ & $0.22(0.02)$ & $0.21(0.03)$ \\
\hline Mean (SD) WA\%* & $72.2(8.2)$ & $71.5(8.4)$ & $69.1(5.9)$ & $66.8(6.7)$ \\
\hline
\end{tabular}

ॠThere was no significant difference between groups 1 and 2, but both groups were significantly greater than either group 3 or 4 (p $<0.001)$, and group 3 was significantly greater than group $4(\mathrm{p}<0.05)$. 

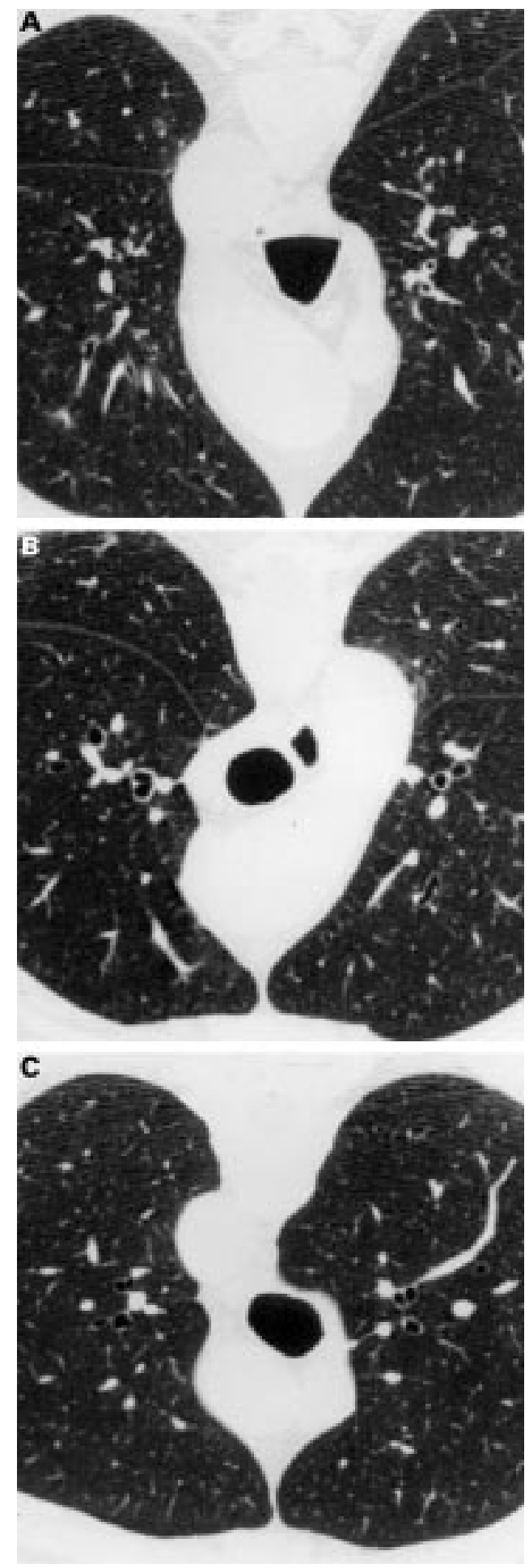

Figure 1 Representative HRCT images of $(A)$ a patient with a history of near fatal asthma, (B) a patient with mild asthma, and (C) a control subject.

PULMONARY FUNCTION TESTS

Spirometric tests were performed according to a standard technique ${ }^{14}$ using computerised pneumotachograph based equipment (Medical-Graphics, St Paul, Minnesota, USA). Lung volumes were obtained by a computerised constant volume plethysmograph (Medical-Graphics) according to the method of Dubois and colleagues. ${ }^{15}$ At least three determinations of functional residual capacity
(FRC) that agreed within 5\% of each other were made, and the average was taken and used to calculate total lung capacity (TLC) and residual volume (RV). Normal predicted values were derived from the equations of Crapo and colleagues. ${ }^{16} 17$

COMPUTED TOMOGRAPHIC SCANS

All subjects had a modified HRCT scan of the chest with a GE Hispeed Advantage (GE Medical Systems, Milwaukee, Wisconsin, USA) using thin section ( $1 \mathrm{~mm}$ collimation) technique, $120 \mathrm{KVp}, 100 \mathrm{~mA}$, one second scan time, and a high spatial frequency (bone) reconstruction algorithm. End inspiratory scans were obtained at five selected levels: superior margin of the aortic arch, tracheal carina, $1 \mathrm{~cm}$ below the carina, inferior pulmonary veins, and $2 \mathrm{~cm}$ above the diaphragm. The images were viewed at a window level of $-450 \mathrm{HU}$ and a window width of $1500 \mathrm{HU}$. The window level of $-450 \mathrm{HU}$ has been shown to be the best level for accurate measurement of bronchial diameters and wall thickness. ${ }^{10}$

Bronchial wall thickness ( $\mathrm{T}$ ) and short axis luminal diameter (L) were measured for all segmental and subsegmental bronchi with a luminal diameter of $1 \mathrm{~mm}$ or more. Only bronchi seen in cross section were analysed. The photographed CT images were enlarged (magnification $\times 5$ ) with the use of an overhead projector and measurements were made using a caliper. The measurements were normalised using the scale on the CT image to obtain absolute measurements of $\mathrm{T}$ and $\mathrm{L}$. The measurements were done by two chest radiologists who had no knowledge of the group to which the subject belonged. A decision was reached by consensus with both radiologists making the assessment together. No assessment of interobserver differences in measurements was made. We did not attempt to assess reproducibility of measurements by doing repeat computed tomographic studies on patients.

Assuming that airway wall thickness is constant in a cross sectional plane, we calculated the total diameter (D) of each airway, $\mathrm{D}=$ $\mathrm{L}+2 \mathrm{~T}$. Luminal area $\left(\mathrm{A}_{\mathrm{i}}\right)$ in $\mathrm{mm}^{2}$ and total airway wall area $\left(A_{o}\right)$ were calculated from $L$ and $\mathrm{D}$, respectively, using the formula $\mathrm{A}=\mathrm{pr}^{2}$. Airway wall area (WA) was calculated as $A_{o}-A_{i}$. We used both the ratio of airway wall thickness to total diameter (the T/D ratio) ${ }^{12}$ and the percentage wall area $\left(\text { WA } \%=\left(W A / A_{o}\right) \times 100\right)^{18}$ to compare airway wall thickening between the four groups.

\section{STATISTICAL ANALYSIS}

All statistical analyses were done using SPSS software. Results were expressed as means (SD). ANOVA was used to compare all HRCT scan measurements and the pulmonary function data between groups. All reported $p$ values are two sided and $p$ values of $\leqslant 0.05$ were considered significant.

\section{Results}

Patient characteristics, lung function data, and current medications are shown in table 1 . As expected, $\mathrm{FEV}_{1}$ was lower in patients with NFA 
and moderate asthma than in those with mild asthma and normal controls. The mean (SD) $\mathrm{FEV}_{1}$ as a percentage of predicted was 68 (20)\% for patients in group 1, 73 (12)\% for group 2, 102 (12)\% for group 3, and 103 (12) \% for group 4 . There were no statistically significant differences in $\mathrm{FEV}_{1}$ between either groups 1 and 2, or groups 3 and 4 . However, both groups 1 and 2 had a significantly lower $\mathrm{FEV}_{1}$ than either group 3 or $4(\mathrm{p}<0.0001)$. Patients in groups 1 and 2 had a higher RV and FRC than those in group $3(\mathrm{p}<0.05$; table 1$)$.

The results of HRCT scan measurements are presented in table 2. Figure 1 shows representative images from three different subjects. There were no statistically significant differences between the groups in the mean number of bronchi measured per patient (table 2). The mean $\mathrm{T} / \mathrm{D}$ ratios and WA $\%$ were 0.27 (0.05) and $78.0(9.2) \%$ for patients in group 1, $0.27(0.05)$ and $78.8(9.2) \%$ for those in group $2,0.25(0.04)$ and $74.2(7.5) \%$ for patients in group 3, and $0.23(0.04)$ and $70.9(8.2) \%$ for the control subjects in group 4 (table 2 ). There was no statistically significant difference between patients with NFA (group 1) and moderate asthma (group 2) in T/D or WA \%. Both groups 1 and 2 had higher T/D and WA $\%$ than either group 3 or $4(p<0.001)$. There were small but significant differences between the patients with mild asthma (group 3) and normal controls (group 4) in T/D and WA $\%$ $(\mathrm{p}<0.03)$. The differences $(95 \% \mathrm{CI})$ between the groups in WA $\%$ were $7.1 \%(95 \%$ CI 0 to 14.4) for groups 1 and $4,3.8 \%(95 \% \mathrm{CI}-3.4$ to 10) for groups 1 and 3 , and $3.3 \%$ (95\% CI -4.4 to 10$)$ for groups 3 and 4 . We repeated the statistical analysis after getting the mean $\mathrm{T} / \mathrm{D}$ ratio and the mean WA\% for each subject. Groups 1 and 2 still had significantly higher $\mathrm{T} / \mathrm{D}$ and WA $\%$ than either group $3(p<0.02)$ or group 4 $(\mathrm{p}<0.002)$. However, the difference between groups 3 and 4 did not reach statistical significance $(p=0.1)$. We then divided the bronchi into large airways with $\mathrm{L}>2 \mathrm{~mm}$ and small airways with $\mathrm{L} \leqslant 2 \mathrm{~mm}$. This subgroup analysis revealed that the differences in T/D and WA $\%$ between the groups was similar for both large and small airways (table 3).

\section{Discussion}

We chose a modified HRCT technique to assess airway dimensions in patients with asthma. The T/D ratio and WA $\%$ were higher in asthma patients with different degrees of severity compared with normal controls. There was no difference in thickening of the airway wall between patients with a history of NFA and patients with moderate asthma who had a similar degree of airway obstruction; however, both these groups had more airway wall thickening than patients with mild asthma. This airway wall thickening was observed in both large and small airways.

Increased airway wall thickness has been recognised as a feature of asthma for almost a century. ${ }^{19}$ Studies of histological specimens obtained from necroscopic studies ${ }^{34}$ and bronchial biopsy specimens ${ }^{20}$ showed that this airway wall thickening is secondary to chronic inflammatory changes. The importance of airway wall thickening in the mechanism of airway narrowing has been discussed. ${ }^{5}$ In summary, the same degree of bronchial smooth muscle contraction in an airway with a thickened wall will result in a greater degree of narrowing than an airway of normal thickness. The measurement of airway dimensions using HRCT scanning has been performed in experimental models ${ }^{10}$ and human subjects. ${ }^{18}$ These studies were done using an HRCT protocol similar to that used here. However, in the previous studies the HRCT images were digitised and the internal and external perimeters were outlined in order to measure bronchial cross sectional areas. Using this technique Okazawa and colleagues ${ }^{18}$ showed that smaller airways $(1.5-6 \mathrm{~mm}$ luminal diameter) of asthma patients were significantly thickened compared with normal controls. Boulet and colleagues ${ }^{12}$ found no difference in the $T / D$ ratio of the bronchus intermedius between asthma patients and normal controls but smaller bronchi were not assessed. We measured airway dimensions of segmental and subsegmental bronchi directly from magnified HRCT images and calculated the cross sectional areas of the airways. We used both the $\mathrm{T} / \mathrm{D}$ ratio as used by Boulet and colleagues ${ }^{12}$ and WA $\%$ as used by Okazawa and colleagues ${ }^{18}$ to assess thickening of the airway wall. Our primary measurement was the $\mathrm{T} / \mathrm{D}$ ratio as $\mathrm{T}$ and D were directly measured from the HRCT images. However, we also assessed the calculated WA and WA\% to compare our results with previous studies. ${ }^{18}$ Okazawa and colleagues $^{18}$ found that the mean WA $\%$ in asthma patients was 84 (3)\% for small airways with luminal diameters of $<2 \mathrm{~mm}$ and 58 (5)\% for large airways with a luminal diameter of $>6 \mathrm{~mm}$. Our results showed that the mean WA $\%$ for all airways assessed was 78 (9.2)\% for patients with NFA, 78.8 (9.2)\% for those with moderate asthma, 74.2 (7.5)\% for patients with mild asthma, and 70.9 (8.2)\% for normal controls. Others have suggested a more complex method of measurement ${ }^{21} 22$ but the gradient in airway thickness from normal subjects to subjects with severe disease suggests that our method is valid. Our method is simpler and less time consuming than that of Brown and colleagues ${ }^{21} 22$ as the measurements are taken directly from the HRCT images and the bronchial cross sectional areas are calculated.

Studies in phantoms have shown that HRCT scanning allows accurate assessment of hollow cylinders ranging from $1 \mathrm{~mm}$ to $5 \mathrm{~mm}$ in diameter with a wall thickness ranging from $0.5 \mathrm{~mm}$ to $2 \mathrm{~mm} \cdot{ }^{23}{ }^{24}$ However, in the current study, as in the previous ones, ${ }^{10}{ }^{18} \mathrm{CT}$ scanning overestimated bronchial wall thickness and underestimated lumen diameter of the airways. The overestimation of bronchial wall thickness on HRCT scans presumably results from the relatively low spatial resolution leading to inaccuracy in boundary detection with volume averaging of the surrounding interstitium and the mucosal folds. However, it should also be realised that studies such as those of James $e t a \bar{l}$ which have measured the airway wall thickness 
in vitro may have underestimated bronchial wall thickness because of the use of fixatives and the lack of airway wall perfusion.

Although others have claimed to measure the entire bronchial wall area, the adjacent pulmonary artery often obscures part of the wall of the bronchus. In these cases the thickness of the airway wall has been assumed to be constant in that area. ${ }^{18} \mathrm{~A}$ potential limitation of our study is that we only measured the bronchial wall considered by two observers to be representative of the average bronchial wall thickness. Furthermore, our results using a single measurement of bronchial wall thickness are similar to the results of Okazawa and colleagues who made measurements of the entire bronchial wall thickness. It should be noted, however, that, regardless of the methods used, bronchial wall thickness is probably overestimated on CT scans because of inaccuracies in boundary detection and inclusion of adjacent peribronchial interstitium. ${ }^{25}$

We chose to study patients with a history of NFA as such episodes are well recognised as being a marker for increased risk of subsequent death from asthma and this group of patients represents a population with the most severe form of asthma. ${ }^{6726}$ We compared patients with NFA with a group of asthma patients who had a similar degree of airflow obstruction and asthma severity (moderate asthma) and a group of patients with mild asthma and normal baseline lung function. We found no difference in airway wall thickening which is a marker of chronic airway inflammation between patients with a history of NFA and those with moderate asthma. This is not surprising as these two groups were matched for their level of airway obstruction and the patients with NFA were studied when they were stable and taking regular anti-asthma medication. Previous studies have shown that asthma patients at risk of death from asthma and patients admitted to hospital with acute asthma are similar with respect to recognised markers of asthma severity and an adequate match for asthma severity can be obtained in case control studies of asthma deaths. ${ }^{27}$ It is interesting to note that even patients with mild asthma had thickening of the airway wall compared with normal controls. The patients with mild disease had a long history of asthma but they were never admitted to hospital and had normal baseline lung function tests at the time of the study. This supports the hypothesis that chronic inflammatory changes lead to airway wall thickening even in patients with mild disease. However, it has been shown in previous studies that the early use of inhaled corticosteroids may prevent the development of chronic airway obstruction ${ }^{28} 29$ and this has been emphasised in national guidelines. ${ }^{30}$ However, it must be emphasised that the difference between patients with mild asthma and normal subjects is small and the clinical significance of this difference is not known. In addition, the statistical significance between mild asthmatic subjects and normal controls was lost when the analysis was performed based on individual subjects after recalculating a mean from each subject rather than taking the mean of all subjects.

The predominant site of airway narrowing in asthma is not clear. However, thickening of the airway wall in patients with fatal asthma was observed in both large cartilaginous and small membranous bronchi. ${ }^{51}$ This thickening occurred predominantly in the small airways of patients with non-fatal asthma. ${ }^{31}$ There was no difference in the thickness of the airway wall at the level of the bronchus intermedius between patients with asthma and normal controls. ${ }^{12}$ In our study we assessed the bronchi at both segmental and subsegmental levels. Unlike Boulet and colleagues we did not measure airway wall thickness of the lobar or main bronchi. We found thickening of the airway wall in both large airways $(\mathrm{L}>2 \mathrm{~mm})$ and small airways ( $\mathrm{L}$ $\leqslant 2 \mathrm{~mm}$ ) of asthma patients compared with normal controls. Our findings are similar to those of Okazawa and colleagues ${ }^{18}$ who found that airways smaller than $6 \mathrm{~mm}$ in luminal diameter of asthma patients were significantly thickened compared with normal controls.

We believe the methodology described in this study would be useful in early intervention studies to see whether more aggressive and earlier anti-inflammatory therapy could prevent some of the changes in the airway wall described here. Although the technique is time consuming and relatively expensive, it offers the opportunity for repeated measurements. The exposure to radiation is a possible concern but the use of the methodology described here would give radiation exposure equivalent to six chest radiographs per assessment.

In conclusion, we have shown with the use of HRCT scanning that patients with asthma of different degrees of severity have more airway wall thickening than normal controls. Furthermore, patients with more severe asthma have more airway wall thickening than those with mild asthma.

The authors thank Dr Peter Paré for reviewing the manuscript and making a number of useful suggestions and Dr Ruth Milner for statistical advice.

1 Aas K. Heterogeneity of bronchial asthma. Allergy 1981;36:3-14

2 Djukanovic R, Roche WR, Wilson JW, et al. Mucosal inflammation in asthma. Am Rev Respir Dis1990;142:43457.

3 Dunnill MS. The pathology of asthma with special reference to changes in the bronchial mucosa. F Clin Pathol 1960;13: 27-33.

4 Dunnill MS, Massarella GR, Anderson JA. A comparison of the quantitative anatomy of the bronchi in normal subjects, in status asthmaticus, in chronic bronchitis and in emphysema. Thorax 1969;24:176-9.

5 James AL, Paré PD, Hogg JC. The mechanics of airway narJames AL, Pare PD, Hogg JC. The mechanics of airway nar.
rowing in asthma. Am Rev Respir Dis 1989;139:242-6.

6 FitzGerald JM, Macklem PT. Fatal asthma. Annu Rev Med 1996;47:161-8.

7 FitzGerald JM, Macklem PT. Proceedings from a workshop on near-fatal asthma. Can Respir f 1995;2:113-25.

8 Paganin F, Séneterre E, Chanez P, et al. Computed tomography of the lungs in asthma: influence of disease severity and etiology. Am $\mathcal{F}$ Respir Crit Care Med 1996;153:110-4.
Lynch DA, Newell JD, Tschomper BA, et al. Uncomplicated

asthma in adults: comparison of CT appearance of the lungs in asthmatics and healthy subjects. Radiology ;188:829-33.

10 McNamara AE, Müller NL, Okazawa M, et al. Airway narrowing in excised canine lungs measured by highresolution computed tomography. F Appl Physiol 1992;73: 307-16.

11 Herold CJ, Brown RH, Mitzner W, et al. Assessment of pulmonary airway reactivity with high-resolution CT. Radiology 1991;181:369-79. 
12 Boulet L-P, Bélanger M, Carrier G. Airway responsiveness and bronchial-wall thickness in asthma with or without 152:865-71.

13 American Thoracic Society. Standards for the diagnosis and care of patients with chronic obstructive pulmonary disease (COPD) and asthma. Am Rev Respir Dis 1987;136:225.

14 American Thoracic Society. Standardization of spirometry: 1987 update. Am Rev Respir Dis 1987;136:1286-96.

15 Dubois AB, Botelho SY, Bedell GN, et al. A rapid plethysmographic method for measuring thoracic gas volume: a comparison with nitrogen washout method for measuring functic

16 Crapo RO, Morris AH, Gardner RM. Reference spirometric values using techniques and equipment that meet ATS recommendations. Am Rev Respir Dis 1981;123:659-64.

17 Crapo RO, Morris AH, Clayton PD, et al. Lung volumes in healthy nonsmoking adults. Bull Eur Physiopathol Respir 1982;18:419-25.

18 Okazawa M, Müller N, McNamara AE, et al. Human airway narrowing measured using high resolution computed tomography. Am 7 Respir Crit Care Med 1996;154:1557-62.

19 Osler W. The principles and practice of medicine. $3 \mathrm{rd}$ ed. New York: Appleton and Company, 1899: 628-30.

20 Jeffery P K, Wardlaw AJ, Nelson FC, et al. Bronchial biopsies in asthma: an ultrastructural, quantitative study and correlation with hyperreactivity. Am Rev Respir Dis 1989;140:1745-53.

21 Brown RH, Zerhouni EA, Mitzner W. Airway edema potentiates airway reactivity. $\mathcal{F}$ Appl Physiol 1995;79:1242-8.
22 Brown RH, Zerhouni EA, Mitzner W. Visualization of airway obstruction in vivo during pulmonary vascular
engorgement and edema. $\mathcal{F}$ Appl Phys 1995;78:1070-8.

23 Webb WR, Gamsu G, Wall SD, et al. CT of a bronchial phantom. Factors affecting appearance and size measurements. Invest Radiol 1984;19:394-8.

24 McNamara AE, Muller NL, Okazawa M, et al. Airway narrowing in excised canine lungs measured by highresolution computed tomography. F Appl Physiol 1992;73: 307-16.

25 Webb WR, Muller N, Naidich DP. High resolution CT of lung. New York: Lippincott-Raven, 1996: 1-40.

26 Richards GN, Kolbe J, Fenwick J, et al. Demographic characteristics of patients of patients with severe life threatening asthma: comparison with asthma deaths. Thorax 1993;48: 1105-9.

27 Rea HH, Scragg R, Jackson R, et al. A case-control study of deaths from asthma. Thorax 1986;41:833-99.

28 Haahtela $\mathrm{T}$, Jarvinen $M$, Kava T, et al. The effects of reducing or discontinueing inhaled budesonide in patients with mild asthma. $N$ Engl f Med 1994;331:700-5.

29 Selroos O, Pietinaloho O, Lofroos A-B, et al. Effect of late versus early intervention with inhaled corticosteroids in asthma. Chest 1995;108:1228-34.

30 Ernst P, FitzGerald JM, Spiers S (eds). Canadian Asthma Guidelines: report from a consensus workshop. Can Respir f 1996;3:89-100.

31 Carroll N, Elliot J, Morton A, et al. The structure of large and small airways in non fatal and fatal asthma. Am Rev Respir Dis 1993;147:405-10. 